\title{
Agricultural Science and Technology Innovation Capability Evaluation Based on Factors Analysis ----- Empirical Study Coming from China's Provinces
}

\author{
Chunmei Wang* \\ College of Economics and Management, China Agricultural University, Beijing 10083, China \\ College of Accounting, Inner Mongolia University of Finance and Economics, Hohhot 010051, China \\ hannahwcm@foxmail.com
}

Keywords: Science and Technology; Innovation Capacity; Factor Analysis; Evaluation

\begin{abstract}
With the increase of constraints factor of environmental resource, China has depended on science and technology (S\&T) innovation to promote agricultural economy from extensive to intensive development, thus the quality and quantity of agricultural products could be improved. Therefore, many countries actively enhance the capability of innovation by strengthening the research input, policy support and better environment. This paper studied the factors that affect innovation capability of China's 31 regions, and constructed a set of evaluation indicators systems based on factor analysis. The result shows that the innovation capability of eastern regions is the strongest, and the innovation capability of middle regions is stronger, then one of western is the weakest.
\end{abstract}

\section{Introduction}

Agricultural S\&T innovation is a kind of science research that government has conducted by policy support and capital investment, in order to meet the needs of modern agricultural industrialization development. The goal of innovation is to accelerate the agricultural economic development by turning research activity into efficient new knowledge and new technology. This process of innovation is not only an industry chain but also a value chain, which integrated the whole process, including research and invention, transfer, demission and application of agricultural achievement. Document No.1 of the Central Committee in 2012 highlighted that agricultural S\&T is a main way to realize the sustained and stable agricultural development and to ensure long-term effective supply of agricultural products. In addition, agricultural S\&T which owes significant public nature, basic and social characteristics is an inevitable choice to ensure national food security and to breakthrough resource and environmental constraints [1]. Therefore, agricultural science and technology plays an important strategic position in China's agricultural economic development. In order to find the factors influencing agricultural S\&T innovation capability, the government, researchers and scholars are very concerned about national or regional S\&T innovation conditions. Then they can find ways to improve scientific and technological innovation level according to the conditions of each region.

In recent years, government and scholars have evaluated S\&T innovation performance from the national or provincial perspective through various indicators and methods. Among them, the main indicators reflect the conditions of inputting human, materials and funds, the quality and quantity of studying achievements, as well as contributing rate to society, economic and environment. Thus, the indicators of evaluating the $S \& T$ innovation performance are different because the point of view is not the same, so that the methods using to evaluate are also distinctive. Y.C. Zhu and Z.J. Huang (2008) found the S\&T innovation capability of China's some regions is not well by using the method of principal component analysis and cluster analysis, and the same time the study showed that there were a much correlation between the level of economic development and the S\&T innovation capability [2]. Q.F. Wang (2009) draw a conclusion that agricultural development influenced much economic after studying the conditions of the county's economic development [3]. L. Xu (2009) 
measured the efficient and capability of agricultural S\&T innovation by establishing a set of evaluation system. On the basis of results, the author compared the agricultural S\&T innovation capability between regions and came to cluster analysis [4]. W.E.J. Ba (2012) evaluated China's S\&T innovation capability using principal component analysis and found that all provinces' innovation capability could be divided into six kinds, and they were in highly uneven [5]. H. Fan (2012) measured all provinces' S\&T innovation efficiency and found that there was feature of periodic fluctuations and evolution [6]. In summary, there are many academic research about S\&T innovation performance on the basis of different principles and indicators system, but the evaluation accord ing to life-cycle theory is not much. The agricultural S\&T innovation capability of 31 provinces are been evaluated from the perspective of research outputs, outcomes and contribution by using factor analysis method.

\section{The Evaluation Indicators System}

Construct Frame. Regional agricultural science and technology innovation capability system includes science research expenditure capability, science research output capability and level of scientific and technological achievements into productivity (Fig. 1) [7]. Researchers can evaluate comprehensively a region' research innovation ability from the three aspects.

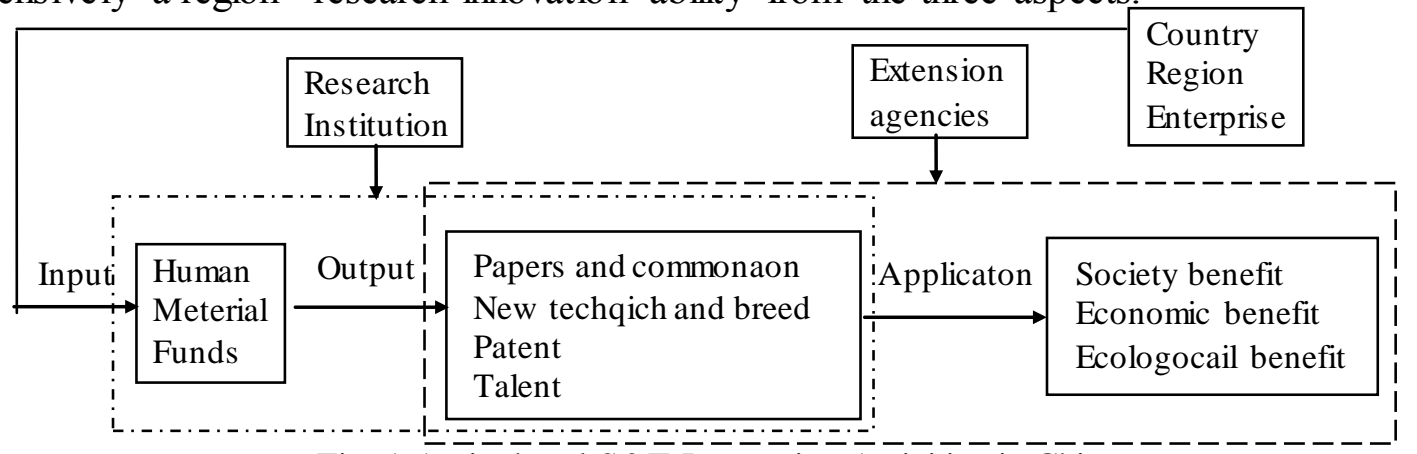

Fig. 1 Agricultural $\mathrm{S} \& \mathrm{~T}$ Innovation Activities in China

Construct indicators system. The research expenditure capability mainly can be reflected by funds, talents, material resources; and the research outputs capability often include academic and technical achievements, which mainly compose of scientific papers, monograph, awards, talents, patents or inventions, national and industrial standard [8]. In additional, capability of achievements into productivity could be reflected in revenue from transfer and licensing of patent ownership, society and economic benefit, ecological environment benefit.

In this paper, 12 evaluation indicators are analyzed to evaluate agricultural S\&T innovation capability (Table 1).

Table 1

\begin{tabular}{|c|c|c|c|}
\hline First level indicators & Second level indicators & Third level indicators & variety \\
\hline \multirow{4}{*}{$\begin{array}{l}\text { The research input } \\
\text { capability }\end{array}$} & Fund & Expenditure on R\&D & $\mathrm{X} 1$ \\
\hline & Human & Number of researchers & $\mathrm{X} 2$ \\
\hline & Policy & S\&T projects & $\mathrm{X} 3$ \\
\hline & Material & Assets expenditure & $\mathrm{X} 4$ \\
\hline \multirow{7}{*}{$\begin{array}{l}\text { The research output } \\
\text { capability }\end{array}$} & \multirow{3}{*}{ Academic achievements } & Published papers in foreign periodicals & $\mathrm{X} 5$ \\
\hline & & Published papers in Chinese periodicals & $\mathrm{X} 6$ \\
\hline & & Publications on S\&T & $\mathrm{X} 7$ \\
\hline & \multirow{4}{*}{ Technical achievements } & Number of patent applications & $\mathrm{X} 8$ \\
\hline & & Number of patent granted & $\mathrm{X} 9$ \\
\hline & & Revenue from transfer of ownership & $\mathrm{X} 10$ \\
\hline & & Number of National and Industrial Standard & $\mathrm{X} 11$ \\
\hline \multirow{3}{*}{$\begin{array}{c}\text { Capability of } \\
\text { achievements into } \\
\text { productivity }\end{array}$} & Society benefit & The net income per farmer & $\mathrm{X} 12$ \\
\hline & Economic benefit & Agricultural GDP per farmer & $\mathrm{X} 13$ \\
\hline & Ecological benefit & Soil erosion control area & $\mathrm{X} 14$ \\
\hline
\end{tabular}




\section{The Evaluation Method of Innovation Capability}

In this paper, these indicators are not related with each other, so the factor analysis is adopted to evaluate regional S\&T innovation capability. As one of the multivariate statistical technique s, factor analysis is to make many observable and related closely indicators a few common factors. Its purpose is to reduce a data set containing a large number of inter-correlated variables to a data set containing fewer hypothetical and uncorrelated components, which nevertheless represent a large fraction of the variability contained in the original data [9].

The mathematical model of factor analysis is: $X=A F+\varepsilon$

$$
X=\left(X_{1}, X_{2}, I I I, X_{p}\right), \text { is original indicators, }
$$

common factors of $\mathrm{X}, \mathrm{A}$ is factor loading matrix, $\varepsilon$ is unique factor. Covariance of the observed variables and extraction factors is factor load, and the factor load can show the degree of correlation between them.

\section{Practical application}

The model's fit. Table 2 shows the value of Sig. was 0.000 , which is smaller than .0 .05 , so there are close correlations between the original varieties. And the value of KMO was calculated to be 0.789 , which falls well within the recommended range $(>0.5)$. Therefore, it is basically suitable to analyze these original variables using factor analysis model.

Table 2 KMO 和 Bartlett 的检验

\begin{tabular}{cccr}
\hline $\begin{array}{c}\text { Sample enough } \\
\text { Kaiser-Meyer-Olkin }\end{array}$ & degree & of & \multicolumn{2}{c}{.789} & \\
\hline Sphericity Test of Bartlett & & & \\
& & Chi-square & 564.219 \\
& approximation & \\
& df & 91 \\
& Sig. & .000 \\
\hline
\end{tabular}

Construct factors variable and model. In order to reflect more information of all indicators, the number of factors were defined as 3 in this case. It can be seen from the data of "Rotation Sums of Squared Loadings" that the two eigenvalues are bigger than 1 and one eigenvalue is every close to 1 . Therefore, it is very suitable to extract three principal components. The data showed that the cumulative variance contribution rate was up to $84.07 \%$ (table 3 ), which is bigger than $80 \%$. So the three principal components can replace the original variables.

\begin{tabular}{|c|c|c|c|c|c|c|c|c|c|}
\hline \multirow[b]{2}{*}{ Component } & \multirow[b]{2}{*}{ Total } & \multicolumn{2}{|c|}{ Initial Eigenvalues } & \multicolumn{3}{|c|}{ Extraction Sums of Squared Loadings } & \multicolumn{3}{|c|}{ Rotation Sums of Squared Loadings } \\
\hline & & $\%$ of Variance & Cumulative $\%$ & Total & $\%$ of Variance & Cumulative $\%$ & Total & $\%$ of Variance & Cumulative \%- \\
\hline 1 & 9.007 & 64.337 & 64.337 & 9.007 & 64.337 & 64.337 & 8.191 & 58.505 & 58.505 \\
\hline 2 & 1.782 & 12.729 & 77.066 & 1.782 & 12.729 & 77.066 & 2.082 & 14.872 & 73.377 \\
\hline 3 & .981 & 7.005 & 84.070 & .981 & 7.005 & 84.070 & 1.497 & 10.694 & 84.070 \\
\hline
\end{tabular}

Extraction Method: PrincipalComponent Analysis.

Rotated component matrix was showed in Table 4. The loading value of common factor F1 is highest on the varieties of X1, X2, X3, X4, X5, X6, X7, X8, X9 and X11. As can be seen, the varieties of $\mathrm{X} 1, \mathrm{X} 2, \mathrm{X} 3$, and $\mathrm{X} 4$ are input indicators of $\mathrm{S} \& \mathrm{~T}$ innovation, such as funds and material; and the varieties of X5, X6, X7, X8, X9 and X11 are output indicators of S\&T innovation activity, such as papers and patents. Thus, F1 can be called as regional S\&T level factor. The loading value of X10 owned the biggest weights in F2 which represented technique production level. At last, the loading value of common factor F3 is highest on the varieties of X12, X13 and X14 which are about technique efficient indicators. Therefore, F3 can be called as regional technique efficient factor. 
The factor score coefficient matrix is gotten by Thanson regression method, and then three liner formula of common factor can be obtained by combining with original indicators.

$\mathbf{F} 3=0.05 z x_{1}+0.66 z x_{2}+1+0.644 z x_{14}$

zxi is normalized value of original data, so the comprehensive score of each regional S\&T innovation capability can be calculated using the formula:

$\mathrm{F}=8.191 \mathrm{~F} 1+2.082 \mathrm{~F} 2+1.497 \mathrm{~F} 3$

The result of 31 provinces' S\&T innovation capability can be seen in table 4

Table 4 S\&T Innovation Capability Comprehensive Score

\begin{tabular}{|c|c|c|r|c|r|r|r|}
\hline Province & Score & Province & \multicolumn{1}{c|}{ Score } & Province & \multicolumn{1}{c|}{ Score } & Province & Score \\
\hline Beijing & 1.964772 & Sanxi & 0.435749 & Tianjin & -0.23398 & Yunnan & -0.47047 \\
\hline Jiangsun & 1.782099 & Heilongiang & 0.324699 & Chongqing & -0.309 & Guizhou & -0.69552 \\
\hline Hubei & 0.847118 & Zhejiang & 0.305859 & Guangxi & -0.32776 & Xinjiang & -0.76341 \\
\hline Shanghai & 0.817438 & Hunan & 0.220788 & Neimenggu & -0.40557 & Ningxia & -0.888 \\
\hline Liaoning & 0.553752 & Heinan & 0.163964 & Fujian & -0.40845 & Hainan & -0.91293 \\
\hline Sichuan & 0.529605 & Anhui & 0.067106 & Jiangxi & -0.42585 & Qignhai & -0.91609 \\
\hline Guangdong & 0.488373 & Hebei & -0.06605 & Gansu & -0.44023 & Xizhang & -1.02078 \\
\hline Sandong & 0.460474 & Jilin & -0.20733 & Shanxi & -0.47038 & & \\
\hline
\end{tabular}

\section{Result Analysis}

According to Table 4, the result shows that the 8 provinces of Eastern region are located in the top 10 in whole country, such as Beijing, Jiangsu, Hebei, Shanghai, Liaoning, Guangdong, Shandong and Zhejiang. Though Tianjin, Fujian and Hainan are located in middle level, most eastern provinces have not only the strongest S\&T innovation capability, but also have higher economic de velopment level. In the central area, the S\&T innovation capability of Hubei is very strong, which lies in the third ranking. Other provinces all are located in the middle 10 in whole country, such as Helongjiang, Hunan, Henan, Anhui, Jilin, Sanxi and Jiangxi. Therefore, the innovation capability of the western regions is relatively week, such as Chongqing, Inner Mongolia, Guangxi, Gansu, Yunnan, Guizhou, Xinjiang, Ningxia, Qinghai and Tibet, except for Sichuan and Shanxi, which rank in the sixth and ninth respectively.

It can be seen that scientific and technological innovation capability of Chinese provinces is reflected in strong cluster effect through score distribution. S\& T innovation capability of most eastern provinces is strongest than other two areas. Among them, Beijing is located in the first place. This is mainly because the first factor's scores of the eastern provinces (level of technological innovation) are sorted at the forefront of the country. This indicates that there are high-quality resources and environment in these provinces, so that researchers can produce so much achievement. At the same time, the S\&T innovation capability of the middle regions is stronger than the western regions.

\section{Summary and Recommendations}

Empirical research shows that the S\&T innovation capability of western regions is far behind eastern regions. Therefore, the Chinese government should take the corresponding measures to facilitate regional coordination of S\&T economic development.

Introducing S\&T talents actively and promoting personnel exchange. Of all the factors, the quality of science and technology talents is one of the most important factors, so the government should take measures to introduce high-quality S\&T talents who can research deeply in all kinds of academic fields. In addition, capital investment is the basic guarantee for talents to carry out research efficiently. At the same time, the government should encourage talents of eastern regions to help western science and technology research or exchange with western talents.

Construct multiple mechanism of agricultural technology transfer. Since the eastern and middle regions have the stronger S\&T innovation capability, so the government should consider how to make their achievement apply all over the country rather than being limited to local regions. In 
addition, agricultural technique owes characteristics of (Quasi) public goods, which need government to transfer from east to west [10]. In this process, the government plays a leading role, because scientific institution is one of key determinant factors to make S\&T achievement useful widely.

\section{References}

[1] Document No.1 of the central committee in 2012. http://www.china.com.cn.

[2] Y.C. Zhu, Z.J. Huang. The regional comparison and analysis on the innovation capability of agricultural science and technology in China. Commercial Research. 9 (2008) 133-136.

[3] Q.F. Wang, Y.G. Dang and L.M. Wang. Study on county economy based on factor and cluster analysis. Application of Statistics and Management. 5 (2009) 495-501.

[4] L. Xu. On science and technology innovation in Chinese agriculture institutes: capacity, efficiency and mod. Doctor paper. Nanjing Agricultural University. 2009.

[5] Bawuerjiang, Y.B. Dong, etc. The evaluation of the regional technology innovation ability based on principal component analysis. Science \& Technology Progress and Policy. 6 (2012) 26-30.

[6] J.F. Lu, B.X. Dai. Efficiency evaluation of technology innovation resource allocation for the technical centers in enterprises. Science Research Management. 1 (2012) 10-18.

[7] L.H. Jiang. Study on theory and method of science and technology innovation for agriculture institutes. Doctor paper. Institute of agricultural information.

[8] X.Y. Zheng, Y. Lou. The influential factors on innovation performance of research team and its mechanism. Studies in Science of Science. 9 (2009) 1428-1438.

[9] F.D. Yin. Exploring the statistical test system of factor analysis. Statistical Research. 6 (2007) 86-90.

[10] J.Q. Zhang. The evaluation about regional technology innovation ability: on the basis of factor analysis. Science and Technology Management Research. 5 (2010) 16-18. 